Review Article

\title{
Antibacterial Therapeutic Agents Composed of Functional Biological Molecules
}

\author{
Dawei Li $\mathbb{D}^{1},{ }^{1}$ Bing Zhou $\mathbb{D}^{1},{ }^{1}$ and Bei Lv $\mathbb{D}^{2}$ \\ ${ }^{1}$ College of Biology and the Environment, The Southern Modern Forestry Collaborative Innovation Center, \\ Nanjing Forestry University, 159 Longpan Road, Nanjing 210037, China \\ ${ }^{2}$ Jiangsu Key Laboratory for Biofunctional Molecules, College of Life Science and Chemistry, Jiangsu Second Normal University, \\ Nanjing 210013, China \\ Correspondence should be addressed to Dawei Li; lida0006@e.ntu.edu.sg and Bei Lv; lvbei@jssnu.edu.cn
}

Received 29 July 2019; Accepted 6 January 2020; Published 29 January 2020

Guest Editor: Maria Grazia Bonomo

Copyright (c) 2020 Dawei Li et al. This is an open access article distributed under the Creative Commons Attribution License, which permits unrestricted use, distribution, and reproduction in any medium, provided the original work is properly cited.

\begin{abstract}
Antibacterial agents are a group of materials that selectively destroy bacteria by interfering with bacterial growth or survival. With the emergence of resistance phenomenon of bacterial pathogens to current antibiotics, new drugs are frequently entering into the market along with the existing drugs, and the alternative compounds with antibacterial functions are being explored. Due to the advantages of their inherent biochemical and biophysical properties including precise targeting ability, biocompatibility, biodegradability, long blood circulation time, and low cytotoxicity, biomolecules such as peptides, carbohydrates, and nucleic acids have huge potential for the antimicrobial application and have been extensively studied in recent years. In this review, antimicrobial therapeutic agents composed of three kinds of functional biological molecules were summarized. In addition, the research progress of antibacterial mechanism, chemical modification, and nanoparticle coupling of those biomolecules were also discussed.
\end{abstract}

\section{Introduction}

Bacteria that cause bacterial infections and disease are called pathogenic bacteria. Antimicrobial therapeutic agents are a group of materials that fight against pathogenic bacteria by killing or reducing the metabolic activity of bacteria. Traditionally, small molecule compounds are the most commonly used agents during the course of antibacterial therapy $[1,2]$. Heterocyclic compounds are organic molecules, which include guanidines derived from carbazoles and azoles and have shown good antibacterial effect [3,4]. Metal ions of heterocyclic compounds play a major role in the antibacterial activities $[5,6]$. For example, the silver $\mathrm{N}$-heterocyclic carbene complexes have good activity against a broad spectrum of bacteria [7]. However, antibiotic resistance becomes an escalating world-wide problem in recent years, and this happens because the diminishing molecules can be produced when the usual strategies was used to screen the libraries of compounds or chemically modify existing antibiotics. Particularly, Gram-negative bacteria are more resistant to antibiotics than Gram-positive bacteria because the outer membrane of Gram-negative bacteria is often hidden by a slime layer, which in turn hides the antigens of the cell. The unique structure of the outer membrane of Gram-negative bacteria prevents certain drugs and antibiotics from entering into the cell, which means these bacteria have increased resistance to drugs and are more dangerous as disease-causing organisms $[8,9]$. Therefore, the alternative antibacterial therapy strategies are being explored $[10,11]$.

Biological molecules are the basic substances that make up life [12]. Antibacterial agents composed of functional biological molecules have been extensively studied in recent years. These new types of antimicrobial therapeutic agents have the advantages of low cytotoxicity and side effects and often show environmental friendliness [13]. Chitosan, for example, is a natural biopolysaccharide and can also be prepared by deacetylation of chitin $[14,15]$. One advantage 
of chitosan over other polysaccharides is that its molecular structure is easy to be modified, especially at the C-2 position, which provides derivatives with different properties. In addition, the strong electrostatic action and the flexibility of the sugar chain make it easy to diffuse into the tissue fluid owing to the surface energy properties.

Antimicrobial peptides (AMPs) are ubiquitous in almost all organisms which can protect the host as the primary first line of defense against invading pathogens [16, 17]. AMPs have the characteristic functions of amphiphilicity and flexible conformational transitions which make the AMPs have the broad-spectrum antimicrobial activity [18]. The unique features and structures of the AMPs make them become particularly interesting compounds for developing new antimicrobial therapies. With the prevalence of antisense antimicrobial therapeutics and application of DNA aptamer $[19,20]$, nucleic acids are also considered to be the promising agents in antibacterial treatment. In this review, the current status of new antimicrobial therapeutic agents composed of functional biomolecules (nucleic acids, antimicrobial peptides, and chitosans) was explored. In addition, the chemical and nanoparticle modification of biomolecules and antibacterial mechanisms are also discussed.

\section{Functional Nucleic Acid}

2.1. Antisense Antimicrobial Therapeutic Agents. The synthetic short single-stranded oligomers can bind to complementary mRNA and inhibit translation or promote degradation of the targeted mRNA in microorganisms. The specific nucleic acid-based antimicrobial therapy confers an advantage over broad-spectrum antibiotics by avoiding unintended effects on commensal bacteria [19]. The reduction of drug discovery time is achieved by a rapid design and synthesis of oligomers based on target RNA sequence in microorganisms, and it also provides a flexible and rational approach to drug development.

Generally, four types of chemically modified nucleic acid analog have been developed. Phosphorothioate oligodeoxynucleotides (S-oligos) are analogs of nucleic acids, in which one of the nonbridging oxygen atoms on the phosphate linkage is replaced by a sulfur atom. The stability of the modified oligonucleotide is dramatically increased when exposed with nucleases [21]. The targeted mRNA can be digested by RNase $\mathrm{H}$ (ribonuclease $\mathrm{H}$ ) when it is trapped with the complementary S-oligos [22]. Fomivirsen is the only commercially available antisense therapeutic agent for the treatment of cytomegalovirus-induced retinitis, and it was approved by USFDA (the United States Food and Drug Administration) in 1998 [23]. Locked nucleic acids (LNAs) and bridged nucleic acids (BNAs) are oxyphosphorothioate analogs that are modified with the extra bridge connecting the $2^{\prime}$ oxygen and $4^{\prime}$ carbon [24]. LNAs and BNAs are also stable to nuclease and may work by targeting mRNA and degrading it with RNase $\mathrm{H}$ [25]. Peptide nucleic acids (PNAs) are analogs of DNA in which the original sugarphosphate backbones are replaced with electrically neutral pseudopeptide linkage $[26,27]$. From the time they were invented in the early 1990s, these new types of DNA mimics have been shown to be capable of invading and opening up duplex structures of DNA effectively through forming new triplex or duplex assemblies with one of the target duplex strands. Owing to its unique mode of action, PNAs have been widely utilized to modulate gene expression and to perform diagnostic functions $[28,29]$. PNAs are uncharged, which in part accounts for their high affinity for RNA. Phosphorodiamidate morpholino-oligomers (PMOs) are also analogs of DNA, in which the ribose is replaced by a morpholine ring and one of the nonbridging oxygen atoms on the phosphate linkage is displaced by a dimethyl amine [30]. PMOs are net neutral in charge and have the characteristic of water solubility and resistance to nucleases. It is believed that PMOs act by sterically blocking initiation of translation and do not activate RNase $\mathrm{H}$ degradation $[31,32]$.

Antisense antimicrobial therapeutic agents could be used against potentially available targets to any gene with a known base sequence in any bacterium in theory. This strategy significantly reduces the time required for discovery of a new antimicrobial. Synthetic nucleic acid oligomers have been synthesized and used as antimicrobial agents over thirty years ago [33]. The substantial improvements have been made until the attachment of cell-penetrating peptides (CPPs) with oligonucleotides was applied [34]. This happens because the biomacromolecule cannot penetrate the cell walls of bacteria, and delivery of synthetic oligonucleotides into the bacterial cytoplasm requires the attachment of another compound that can penetrate the bacterial cell wall. It is known that fts $Z$ in $S$. aureus is required for cell division, which was designed to be a target for a peptide-conjugated PNA (PPNA) [35]. Wesolowski et al. also reported that a CPP-PMO complex targets E. coli gyrA that is a conserved gene multiple bacterial species [36]. The sensitivities of a variety of both Gram-positive and Gram-negative bacterial strains to the CPP-PMO were tested, and the results showed that CPP-PMO reduced the viability of in four kinds of bacterial strains and CPP-PNA targeted the gyrase in another one. The expression of mRNA of gyrA was reduced, and the bacterium multiplication was inhibited. Furthermore, the CPP-PNA was synergistic with various current antibiotics [37].

2.2. Aptamer. Aptamer is an oligonucleotide selected from the library of nucleic acid molecules by a screening technique called SELEX (systematic evolution of ligands by exponential enrichment) in vitro [38]. Aptamers have been widely studied as antibacterial and anticancer agents because of the advantages of specific and accurate targeting, low cytotoxicity, easy preparation, and short research and development period [39]. Aptamer usually has a short sequence of 15-60 nucleotides. The intrastrand base pairing within aptamer can form stable secondary structures that has the special ability to bind targets with high affinity and specificity. In addition, aptamer can be extensively modified by chemical synthesis [40]. In the aptamer-based antibacterial agent development, limitations of traditional antibiotic selection such as accumulation in cells and the size and 
charge of candidate drugs could be broken [41]. The diversity of single-stranded nucleic acid structures and spatial conformations provides the specific binding ability with various target molecules, and the highly specific binding forces may be caused by van der Waals forces, hydrogen bonding, electrostatic interactions, and shape matching [42]. Aptamers exert antimicrobial effects through completely different mechanisms compared to traditional antibiotics. It has been reported that a aptamer has the ability to combine surface antigens with passively neutralizing pathogens and then inhibit bacterial growth [43-45]. Aptamers can also target a particular factor, a key protein, for example, and then block the key biochemical process with actively neutralizing pathogens [46].

It had demonstrated that the binding of $\mathrm{TiO}_{2}$ particles to the aptamer (E. coli-specific ssDNA) enhances the inactivation effect to of E. coli [47]. As shown in Figure 1, the close contact of the functionalized particles with $E$. coli was achieved by the strong binding effect between the aptamer and its target on the surface of $E$. coli, which can effectively induce reactive oxygen and be rapidly transferred to the cells. The aptamer-nanoparticle complexes may become a new generation of drug delivery systems with a higher specificity and effectiveness $[48,49]$.

2.3. Topoisomerase Inhibitors. Topoisomerases are essential enzymes which have the special ability to change the topological structures of DNA by cleaving the DNA backbone and then rejoining it in the cells [50-52]. Those ubiquitous proteins are reported to be involved in many cellular processes such as replication, transcription, recombination, and critical for cell growth and proliferation [53-55]. For the importance of their cellular role, some topoisomerases are reported to be selected as the targets of anticancer drugs and antibiotics [56-58]. Bacterial-type IIA topoisomerases, topoisomerase IV, and DNA gyrase, for example, are well utilized clinical targets for antibacterial chemotherapy [59-61]. However, resistance of bacterial pathogens to current antibiotics has grown to be an urgent crisis. Compounds that can inhibit the activities of bacterial-type IA topoisomerases have been extensively studied in recent years [62-65].

Yang and coworkers reported that linear oligonucleotides containing mismatch or bulge can act as the irreversible inhibitors of bacterial topoisomerase I [66, 67], but no direct evidence such as the formation of covalent complex between DNA and proteins was provided in their studies. In our recent studies, particularly designed small DNA circles with high bending stress were synthesized [68]. It is demonstrated that small DNA circles showed high inhibitory effect on the activity of bacterial topoisomerases I and the single-stranded regions associated with bending deformation in DNA circles are believed to be the crucial factor for trapping the enzymes and decreasing the effective concentration of the topoisomerase in the reaction solution, as shown in Figure 2 [68]. Although DNA-based biopharmaceuticals have the advantages of low cytotoxicity and can be prepared easily [69, 70], the risk of host genome integration should be taken into consideration during the further design of the new type of

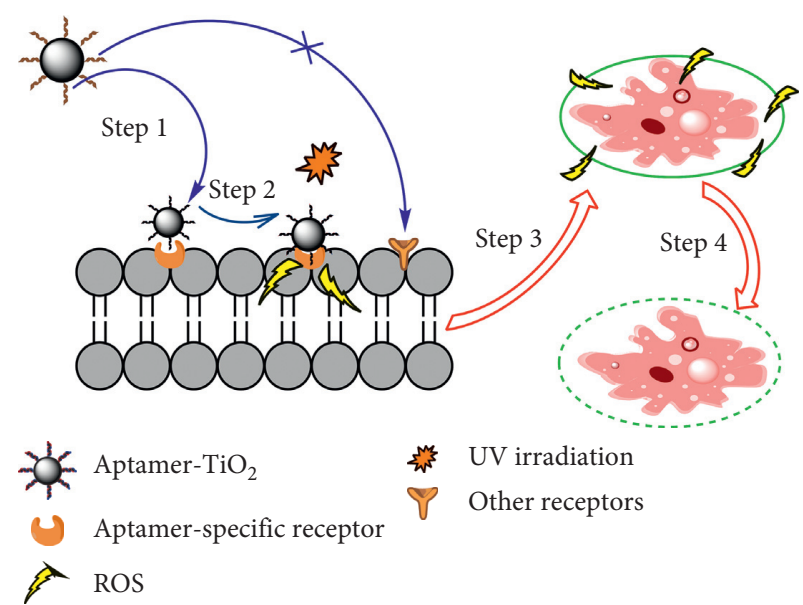

FIGURE 1: Schematic diagram of antibacterial mechanism of aptamer$\mathrm{TiO}_{2}$. Step 1: $\mathrm{TiO}_{2}$ particles conjugated with aptamer bind on the cellular surface. The aptamer specifically recognizes its receptor on the bacterial surface to make the $\mathrm{TiO}_{2}$ particles closely contact with the cell membrane. Step 2: $\mathrm{TiO}_{2}$ is excited under UV irradiation to generate electrons on its surface and produce reactive oxygen species (ROS). Steps 3 and 4: ROS causes oxidative damage to bacteria by disrupting the cell wall or damaging DNA/RNA and proteins.

DNA-based antibacterial agents. In addition, it should be pointed out that the small DNA circles alone can hardly penetrate into bacteria and exhibit bacteria growth inhibition effect in the current stage. However, it is possible to facilitate the delivery of oligonucleotides into bacteria with the development of the drug-delivery carriers based on nanotechnology and pharmaceutics.

\section{Antimicrobial Peptide}

Antimicrobial peptides (AMPs) are usually short biomolecules (15-50 amino acids) encoded by genes [71]. Most of these short peptides contain basic amino acids and hydrophobic residues, which are arranged in three dimensions on the surface of the peptide. The earliest research on AMPs can be traced back to the time when Fleming discovered lysozyme [72]. This discovery has developed a new field of research. In the 1960s, Zeya discovered that the basic peptides in polymorphonuclear (PMN) have antimicrobial properties $[73,74]$. Over time, cecal peptide was discovered in 1980s [75]. The discovery and identification of defensive peptides from mammalian granules of neutrophils have taken a major step in the study of AMPs. In 1987, it was found that AMPs were rich in Xenopus laevis, named "magainins" [76]. Magainins were obtained by the secretory gland in the body. It also showed for the first time that AMPs are not only molecules of lower invertebrates but also part of higher vertebrates. Ever since, researchers around the world have made outstanding contributions to the continued rapid development of AMPs.

3.1. AMP Classification. Thousands of AMPs have been extracted from single-celled microorganisms of plants, insects, and bacteria. The antimicrobial peptide database (APD3) 


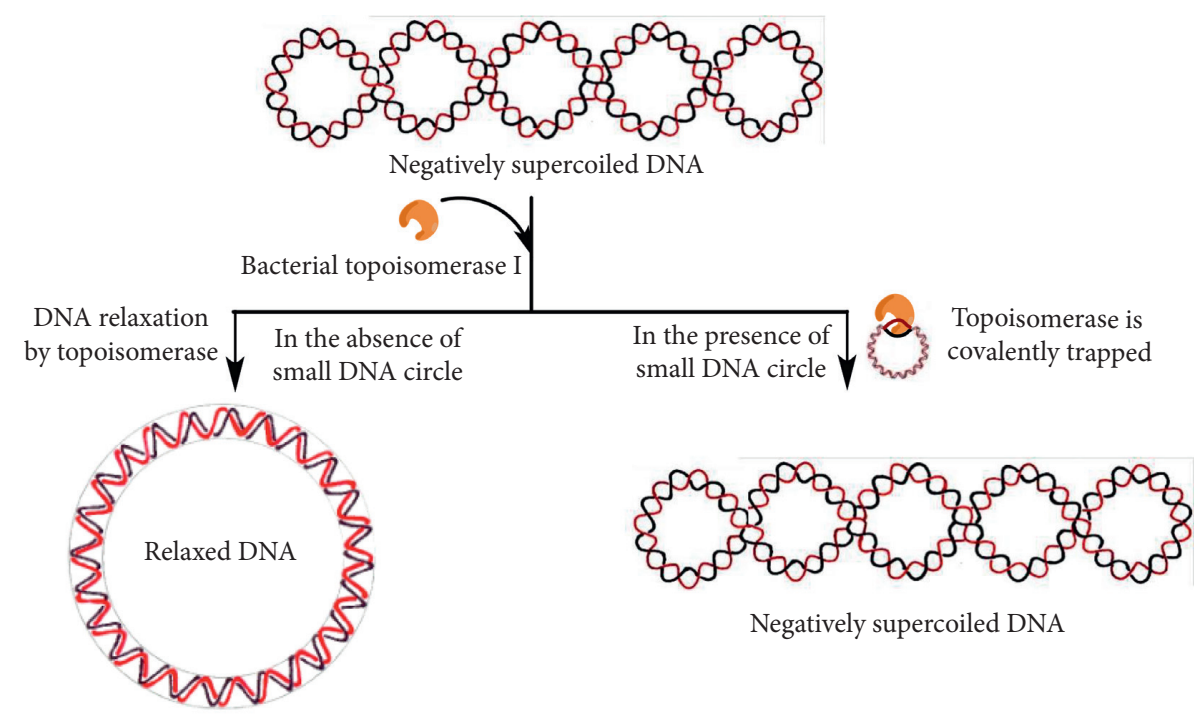

FIGURE 2: Illustration of the supercoiled plasmid relaxation catalyzed by bacterial topoisomerase I in the presence or absence of small DNA circle.

contains more than 3000 AMPs $[77,78]$. It is worth noting that bacteria also produce a variety of AMPs in order to limit the growth of other microorganisms. AMPs can be ranked according to their physical properties, sequence properties, and conformation of antimicrobial peptides interacting with cell membranes. The APD3 database divides them into animal AMPs, plant AMPs, and bacterial AMPs, as shown in Table 1. Animal AMPs are further divided into human AMP, bovine AMPs, porcine AMPs, and insect AMPs [77].

\subsection{Animal AMPs}

3.2.1. Human AMP. It has been known that many patients with chronic obstructive pulmonary disease (COPD) sustain bacterial adhesion infections. Peptide deaminase (PADI) levels are used to elevate when suffering from COPD [97]. It is found that LL-37 was citrated due to an excess of PADI, which made the peptide more susceptible to be degraded by proteases. Citrated LL-37 reduced the antimicrobial activity against Haemophilus and S. aureus. Lima evaluated several HDPs including LL-37 and found that LL-37 had good potential in antimicrobial and immunomodulatory activities [98]. The antimicrobial effect of exogenous LL-37 was studied on the preterm infants in vitro, and the results indicated that LL-37 can enhance host immunity and exhibit significant anti-SA, SE, and CA activities [99] (SA, SE, and CA represent Staphylococcus aureus, Staphylococcus epidermidis, and Candida Albicans, respectively). L-37 and its homologues may be promising drugs for the prevention or treatment of neonatal sepsis.

3.2.2. Bovine and Porcine AMPs. Baumann et al. reported that bovine cathelicidins had the ability to inhibit bacterial growth and enhance the host immune system [100]. The results showed that BMAP-27 had the best killing effect on $S$. aureus, E. coli, and Streptococcus uberis (three main mastitis pathogens causing bovine mastitis). Pore-forming ability and antimicrobial mechanism of BMAP-27 are similar to LL-37 which has the amphiphilic alpha helix structure leading to membrane rupture. Surprisingly, although BMAP-27 completely lost its amphiphilic character, it still showed antimicrobial function, indicating the net charge contributing partially to the bactericidal effect.

PMAP-36 was isolated from porcine and has a variety of immunomodulatory effects in vitro [101]. It was found that PMAP-36 can disrupt the inner membrane of bacteria and is still active with a significant antibacterial effect at the concentration as low as $2.5 \mu \mathrm{M}$ [101]. Modified PMAP-36 analogs were also designed in another work. It showed that the original antibacterial activity was retained when shortening the length of peptide chains within a certain range, and the hemolysis rate was also reduced at the same time [102]. Appropriate modification of existing AMPs may provide a promising strategy for developing new agents to overcome drug resistance.

3.2.3. Insect AMPs. Insect AMPs also show stronger antimicrobial effects at low concentrations. Abaecin showed no detectable activity against $E$. coli when tested at a concentration of $200 \mu \mathrm{M}$ alone, and hymenopteran can affect the growth of bacterial cells only at concentrations greater than $2 \mu \mathrm{M}$ [103]. However, the effective concentration of hymenopteran is $1.25 \mu \mathrm{M}$ and was observed when it was used in combination with abaecin. The result indicated that abaecin can enhance the interactions between $E$. coli and hymenopteran. The naturally occurring enhanced interactions suggested that the combination of AMPs can be used to treat against Gram-negative pathogens with acquired resistance [104].

\subsection{Plant AMPs}

3.3.1. Brassica AMPs. Plant AMPs mainly interact with phospholipids in the microbial cell wall and lead to 
TABle 1: Physicochemical properties of AMPs mentioned in this review.

\begin{tabular}{|c|c|c|c|c|c|c|c|}
\hline Tree & Source & Peptide & Length & Net charge & Hydrophobic residue (\%) & 3D structure & Reference \\
\hline \multirow{8}{*}{ Animal } & Human & LL-37 & 37 & 6 & 37 & Helix & [79] \\
\hline & \multirow{2}{*}{ Bovine } & Bactenecin & 12 & 4 & 66 & Unknown & {$[80]$} \\
\hline & & BMAP-27 & 27 & 10 & 40 & Helix & {$[81]$} \\
\hline & Chicken & CATH-2 & 27 & 9 & 37 & Helix & {$[82]$} \\
\hline & \multirow{2}{*}{ Porcine } & PMAP-36 & 37 & 13 & 37 & Helix & {$[83]$} \\
\hline & & Protegrin & 18 & 7 & 44 & Beta & {$[84]$} \\
\hline & Honeybee & Abaecin & 34 & 4 & 23 & Rich & {$[85]$} \\
\hline & Tsetse & Cecropin & 17 & 8 & 47 & Helix & {$[86]$} \\
\hline \multirow{5}{*}{ Plant } & Brassica & BhDef1-2 & - & - & - & - & [87] \\
\hline & Aizoaceae & Novel peptides & - & - & - & - & {$[88]$} \\
\hline & Alfalfa & alfAFP & 45 & 3 & 33 & Bridge & {$[89]$} \\
\hline & Vigna radiata & $\operatorname{Vrd} 2$ & 47 & 3 & 29 & Combine helix and beta structure & {$[90]$} \\
\hline & Potato & Snakin-1 & 63 & 8 & 31 & Helix & {$[91]$} \\
\hline \multirow{5}{*}{ Bacteria } & \multirow{2}{*}{ Paenibacillus } & Nisin & 43 & 1 & 34 & Nonhelixbeta & {$[92]$} \\
\hline & & TriA1 & 13 & 2 & 46 & Nonhelixbeta & [93] \\
\hline & \multirow{2}{*}{ Pediococcus } & Pediocin & 44 & 3 & 34 & Combine helix and beta structure & {$[94]$} \\
\hline & & LMW & 16 & 1 & 50 & Unknown & {$[95]$} \\
\hline & Pediococcus & Garvicin KS & 60 & 5 & 60 & Unknown & [96] \\
\hline
\end{tabular}

membrane penetration [105]. Two new defensin genes, BhDef1 and BhDef2, were isolated from the Brassica hybrid cv Pule by Kaewklom et al. [87]. Six of the eight synthetic BhDef polypeptides have antimicrobial activity against Gram-positive and Gram-negative bacteria. Among them, BhDef14 had the highest activity against the two test pathogens MRSA and Salmonella typhi with an MIC of $1.88 \mathrm{mg} / \mathrm{ml}$ and $0.66 \mathrm{mg} / \mathrm{ml}$, respectively.

3.3.2. Portulaca AMPs. Samriti et al. isolated new AMPs from the leaves of Portulaca oleracea [88], which had antimicrobial activity against $S$. aureus and Bacillus subtilis, but no antimicrobial activity against E. coli and Candida albicans [106]. The existence of omptins may be the cause of this phenomenon, a class of proteases present in the outer membrane of Gram-negative bacteria. Bacterial proteases have the ability to convert active AMPs into inactive fragments, making host bacteria resistant to these active AMPs. Another reason may be the low concentration of protein/ peptide, resulting in insufficient supply of protein. In addition, the maximum inhibition zone against $S$. aureus and Bacillus subtilis was $8 \mathrm{~mm}$ and $4 \mathrm{~mm}$, respectively, using the agarose diffusion method [106].

3.3.3. Alfalfa AMPs. It has demonstrated that chitin-binding domain (CBD) may increase the antimicrobial activity of alfAFP, one peptide from Alfalfa [107]. The results suggested that the introduction of this recombinant gene into other crops such as potatoes may result in GM crops (genetically modified crops) having higher resistance to fungal pathogens. Badrhadad et al. put the restructuring gene into tobacco by agrobacterium-mediated transformation, forming the recombinant protein (CBD-alfAFP) [108]. The experimental results showed that the total protein extract obtained from the transgenic plants $(P<0.05)$ significantly inhibited the growth of various bacteria and fungi compared with the nontransgenic plants, indicating fusion of CBD and alfAFP is an effective way to control pathogen damage.

3.4. Bacterial AMPs. The nisin synthesized by lactic acid bacteria $(\mathrm{LAB})$ can suppress bacteria proliferation and was used as a natural preservative [109]. The study indicates that adding bacteriocin to packaging materials is an effective way to improve meat fresh keeping, rather than adding it directly to meat. In addition, nisin is nontoxic and can be digested by proteases with little or no effect on intestinal flora [110]. Finding new strategies based on synergistic combinations is key to fight resistant bacteria. Combinations of different bacteriocins can synergistically or additively eliminate bacteria [111]. The synergistic effects of the four bacteriocins nisin, pediocin, and enterocin MT104b and MT162b were studied based on food spoilage bacteria using the checkerboard method. The results showed that nisin combined with MT104b had a synergistic effect on killing S. aureus, while nisin combined with pediocin, nisin combined with MT162b, pediocin combined with MT104b, and pediocin combined with MT162b had a synergistic effect on Sakei. When Nisin is combined with pediocin, it has an additive effect on Listeria monocytogenes [111].

Recent work also conducted in-depth research on the synergistic bacteriocins. The activity of garvicin KS, a novel bacteriocin produced by Lactococcus garvieae, was studied $[112,113]$. Unlike other bacteriocins, garvicin KS inhibits Acinetobacter but does not inhibit other Gram-negative bacteria. The combination action of polymyxin B and garvicin KS has a synergistic effect on Acinetobacter and E. coli, but not on $P$. aeruginosa. The mixture of nisin and polymyxin B has a similar effect. The synergistic mixture of polymyxin $\mathrm{B}$, garvicin $\mathrm{KS}$, and nisin resulted in rapid and complete eradication of Acinetobacter and E. coli. Low concentrations of garvicin KS or nisin can also rapidly and completely eliminate $S$. aureus when bacteriocins work synergistically with farnesol. In addition, garvicin KS is also 
used as a promising healing AMP due to broad-spectrum inhibition and synergy with other antibiotics [114].

3.5. Mechanism of Action of AMPs. Most bioactive peptides are initially present as inactive precursors and are released in different ways in vivo $[115,116]$. Generally, AMPs are released from their precursor proteins and participate in immune response. Several models, for example, "barrelrod model," "carpet model," and "ring hole model," have been proposed to explain peptide insertion and membrane permeability, as shown in Figure 3. It is believed that the positively charged AMPs first interact with the negatively charged lipid groups on the outer surface of the cell membrane [117]. The amphiphilic feature facilitates the alternative insertion of the hydrophobic residue in AMPs. When the concentration of AMPs is relatively low, the peptide binds in parallel with the lipid bilayer. Once a certain threshold concentration is reached, the peptide molecule is perpendicular to the membrane and inserted into the lipid bilayer to form a transmembrane pore [118]. During the course of this action, spontaneous conformation changes in AMPs cause their disturbance in the cell membrane. Changes in the membrane structure, such as thinning, formation of pores, and localized disturbances, may result in the reorientation of peptide molecules in the membrane, and AMPs may also migrate through the membrane and diffuse into the cytoplasm to reach the intracellular target region [119]. The binding of AMPs on the surface of the cytomembrane changes the potential structural properties difference inside and outside the bacterial cell membrane and leads to dysregulation of ion channels and disorder of intracellular ion balance, which ultimately causes death of the bacteria [120]. Mammals, however, can produce proteases that has an ability to digest most of AMPs efficiently [121]. In addition, mammalian cell membranes are neutral, and the cholesterol can also stabilize the cell membrane structure, which is another reason that the activity of AMPs is alleviated in mammalian cell membranes [121]. The facts mentioned above indicate that AMPs can be used as excellent bacteriostatic agents for low toxicity to the human body.

\section{Chitosan}

Chitosan is a natural nontoxic biopolymer derived by deacetylation of chitin, a major component of the shells crab, shrimp, and crawfish. Many attentions have been attracted because of its unique biological activities and pervasive application in biopharmaceutical and chemical industries. The molecular weight of chitosan is between 3,800 and $20,000 \mathrm{Da}$, and the ratio of D-glucosamine to N-acetyl-Dglucosamine in polymer chain is known to be the degree of deacetylation (DD) that determines most of properties of chitosan [122]. As a polycationic polymer, chitosan has been investigated as an antimicrobial material against a wide range of target organisms like algae, bacteria, yeasts, and fungi [123-125].
The use of chitosan is limited because of its insolubility in water, high viscosity, and tendency to coagulate with proteins at high $\mathrm{pH}$. Many efforts to prepare functional derivatives by chemical modifications to increase the solubility in water have been reported [126]. In order to address the problem, scientists expand the application range by chemical modification of the chain without changing the original backbone, as shown in Figure 4 [127]. In addition, with the development of nanometer materials, researchers have turned their studies to the formation of chitosan nanoparticle complex that can improve their performance in antimicrobial behaviors [128].

\subsection{Chitosan Derivatives}

4.1.1. Quaternized Derivatives. In order to overcome the fact that chitosan is only suitable for acidic conditions, scientists make quaternized nitrogen atoms to produce derivatives with long-term charge and good water solubility (a wide range of $\mathrm{pH}$ values). For example, $\mathrm{N}, \mathrm{N}, \mathrm{N}$-trimethyl chitosan is the first quaternized chitosan derivative with good antimicrobial activity [135], and improved antibacterial activity can be achieved by extensive quaternization of chitosan, as shown in Table 2. It has been demonstrated that low concentration of trimethyl chitosan (TMC) appears to be more effective against $E$. coli. The maximum activity is attained when $1 \mathrm{mg} / \mathrm{ml}$ of TMC was used [136]. In another studies, researchers synthesized three different ammonium salts with carboxylic acid end groups by the quaternary reaction of bromohexanoic acid with tertiary amines. The complexes were then coupled to the chitosan skeleton. The results showed no significant change in the antimicrobial activity against $S$. aureus. However, improved antimicrobial efficiency against $P$. aeruginosa was observed under the same condition [137]. Moreover, the quaternized derivatives exhibited good thermal stability, which is suitably applied to later development and utilization [138].

4.1.2. Sulfonated Derivatives. Sulfonated chitosan (SCS) was prepared by attaching 1,3-propane sulfonate to the chitosan backbone. Dragostin et al. measured the minimum inhibitory concentrations (MICs) and minimum bactericidal concentrations (MBCs) of sulfonated chitosan derivatives using broth microdilution methods, and antimicrobial activity of the designed derivatives is higher than pure chitosan [134]. It is shown that the most active derivative is chitosansulfadiazine, and its MIC value is 0.03 and $1.25 \mathrm{mg} / \mathrm{mL}$ against $E$. coli and $S$. aureus, respectively, which is much lower than the values of unmodified chitosan. The promising antimicrobial activity is believed to be closely connected with the sulfonamides that replace chitosan glucosamine [134]. In addition, the in vivo models studies of rat burn wound showed that chitosan-sulfonamide derivatives have better healing effects than unmodified chitosan and can enhance epithelial formation. The MIC values against $E$. coli and $S$. aureus were also messaged in the studies, and the antibacterial activity increased by four times than those of water-soluble chitosan [130]. 


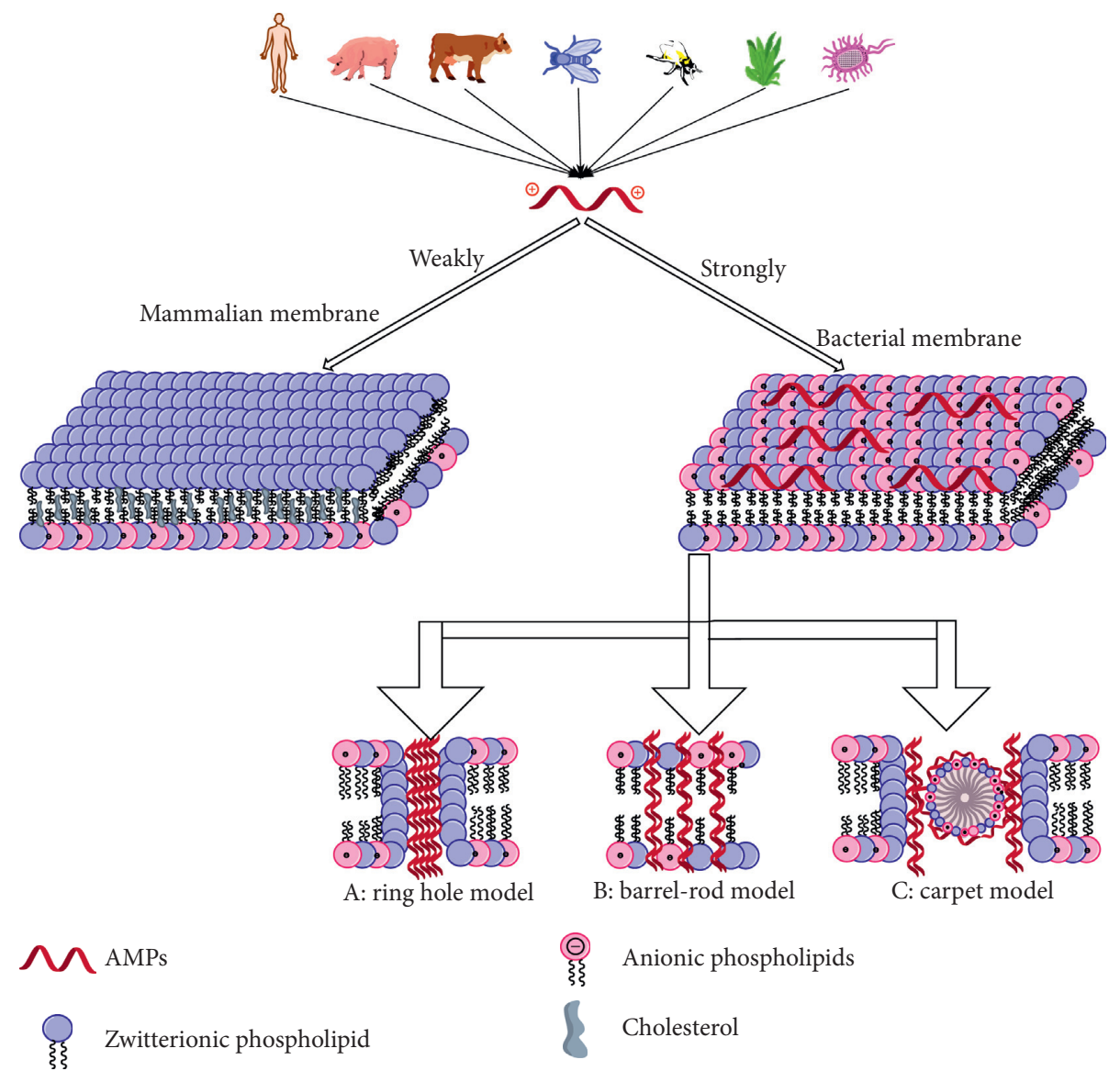

Figure 3: Mechanism of antibacterial peptides (AMPs): (a) in the ring hole model, the peptides insert into the membrane and aggregate into unstructured micelles by inducing continuous bending of the lipid monolayers; (b) in the barrel-rod model, the peptides vertically insert into the hydrophobic core region of the lipid membrane to form pores, like the rod inside the barrel; (c) in the carpet model, the peptides cover the membrane like a carpet, destroying the cell membrane and eventually leading to the formation of micelles. Due to the structural difference between the cell membrane of mammalian and bacterial, AMPs weakly react to mammalian cell membranes, but strongly to bacterial cell membranes.
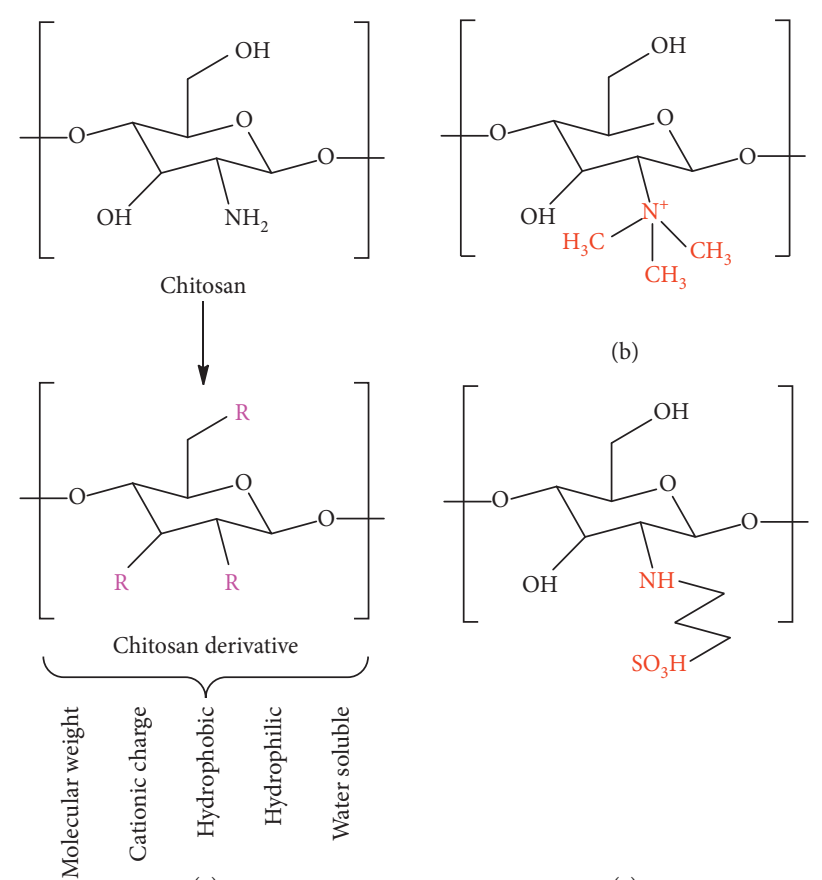

(b)

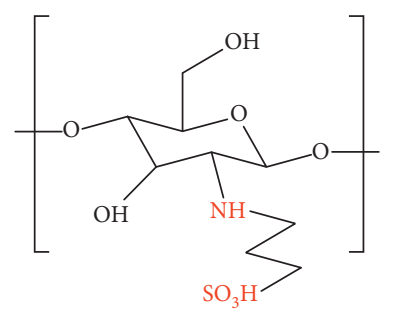

(a)

(c)

FIGURE 4: Chemical structures of (a) chitosan, (b) trimethyl chitosan (TMC), and (c) sulfonated chitosan (SCS). Chitosan derivatives with different properties can be prepared by modification at $R$ ( $R$ quaternary ammonium, sulfonation, hydroxyalkyl, alkyl, and aminoalkyl). 
TABLe 2: MIC $(\mu \mathrm{g} / \mathrm{mL})$ of chitosan and its derivatives against $E$. coli and $S$. aureus.

\begin{tabular}{lccc}
\hline & \multicolumn{3}{c}{ MIC $(\mu \mathrm{g} / \mathrm{mL})$} \\
& E. coli & S. & Reference \\
& aureus & \\
\hline Chitosan & $>256$ & $>256$ & {$[129-134]$} \\
N-Hydroxypropyl chitosan & 31.3 & 31.3 & {$[129]$} \\
N-Aminoethyl chitosan & 62.5 & 125 & {$[131]$} \\
N-Ethyl chitosan & 64 & 32 & {$[132]$} \\
N-Dodecyl chitosan & 128 & 64 & {$[132]$} \\
2-Hydroxy-3-trimethylammonium & 31.25 & 7.8 & {$[133]$} \\
chitosan & - & 30 & {$[134]$} \\
Sulfadiazine chitosan & & &
\end{tabular}

\subsection{Chitosan Nanoparticle Complexes}

4.2.1. Chitosan-Ag Complex. Chitosan has high chelating ability with various metal ions under acidic conditions. It is well known that metal ions can bind to the cell wall of microbial molecules, and it may be fatal to bacteria. Chitosan-mediated chelation of metal ions is often considered as a possible way to perform its antimicrobial action [139]. Silver ions can attach to proteins on the surface of cell membranes, which can cause changes in the structure and permeability of the cell membrane, ultimately leading to bacterial death [140]. In addition, silver ions can interact with microbial nucleic acids to inhibit microbial replication [140]. Chitosan metal complexes have strong antimicrobial activity. Kalaivani et al. used chitosan-mediated silver nanoparticles to detect the zone of Bacillus sp. and S. aureus by the agar disc diffusion method [141]. The inhibition diameters were $15 \mathrm{~mm}$ and $13 \mathrm{~mm}$, respectively. At the same time, ampicillin and amphotericin- $\beta$ were used as comparison to determine their antimicrobial activity against bacteria and fungi. The zone of inhibition diameters was smaller than chitosan-mediated silver nanoparticles, indicating the complexes had high antimicrobial activity.

4.2.2. Chitosan- $\mathrm{ZnO}$ Complex. It has been reported that $\mathrm{ZnO}$ nanoparticles release reactive oxygen species (ROS) [142]. ROS and $\mathrm{Zn}^{2+}$ can attack the negatively charged cell wall and cause bacterial leakage, eventually leading to bacterial death. In another studies, a porous chitosan film was prepared by casting chitosan- $\mathrm{ZnO}$ complex on silicon microsphere. By testing the efficiency against Gram-negative bacteria Klebsiella and Gram-positive bacteria Bacillus, it showed that the chitosan- $\mathrm{ZnO}$ composite film has the better antibacterial and antifouling activities when compared with the chitosan synthesized in acid solutions [143]. In addition, the complex showed more inhibition to Klebsiella than Bacillus. This difference may be caused by the chemical composition and structure of the cell membranes of the two bacteria. Recently, an unfocused chitosan/ZnO composite film was first prepared by a simple one-pot procedure [144]. The antimicrobial activities of chitosan against $S$. aureus and $E$. coli were studied by the colony counting method. Antimicrobial analysis showed that the effectiveness of all composite film can catch up to 2-4 times compared with pure chitosan. In another study, scientist successfully synthesized zinc oxide nanoparticles by microwave heating using chitosan as a stabilizer [145]. The amount of zinc oxide particles show linear relationship with the antibacterial activity. The antimicrobial activity of the complex against $S$. aureus and E. coli was determined to be $16 \mathrm{~mm}$ and $13 \mathrm{~mm}$ by measuring the inhibition zone. On the contrary, the optical density of the complex as an inhibitor is more than 1.5 times than pure chitosan when cultured at $37^{\circ} \mathrm{C}$ for 12 hours.

4.3. Mechanism of Action of Chitosan. Chitosans showed higher antibacterial activities than chitosan oligomers and markedly inhibited growth of most bacteria tested although inhibitory effects differed with Mws of chitosan. Li et al. studied the effects of different degree of deacetylation (DD) and $\mathrm{pH}$ on the antimicrobial activity of ultrahigh molecular weight chitosan [146]. The results showed that the antimicrobial activity against $E$. coli and $S$. aureus enhanced with the increase in chitosan DD when $\mathrm{pH}$ was 6.0. The minimum bactericidal concentration of chitosan amphiphilic bacteria was $0.0156 \%$, when DD gets to $100 \%$. The ultralong molecular chain of high-molecular-weight chitosan facilitates the combination of bacteria and then significantly enhances its antimicrobial activity. The nature of the antimicrobial activity is also relevant to the protonation of the amino groups and the formation of cations [147]. It is characterized by inhibiting bacterial growth first, and then the cells gradually break down in the bacteriostatic process.

The antimicrobial activity mainly depends on the presence of $-\mathrm{NH}_{3}$. According Gomes' reports, it is proved that the surface of the nanomembrane with the highest antimicrobial activity had more $\mathrm{NH}^{3+}$ groups [148]. $\mathrm{Nu}$ merous studies have shown that the $\mathrm{NH}^{3+}$ group of chitosan can interact with the negatively charged components carried by bacteria, causing a dramatic change on the membrane surface. This process increases membrane permeability, leads to cell membrane instability, induces leakage of intracellular components, and ultimately leads to cell death. It is also suggested that the chelation ability of chitosan has an important influence in antimicrobial ability [139]. Chitosan binds to trace metals on the surface of the cell wall, competing with $\mathrm{Mg}^{2+}$ and $\mathrm{Ca}^{2+}$ for electronegative sites. Owing to the substitution, the cell wall may lose its integrity or affect the activity of the degrading enzyme, making the cells unable to grow normally. The other mode of antimicrobial action proposed relies on the ability of chitosan to interact with cellular RNA through the cell membrane, then inhibiting DNA transcription and protein synthesis [149]. Besides chitosan, natural antimicrobials, including plant extracts and their essential oils, enzymes, peptides, bacteriocins, bacteriophages, and fermented ingredients, have all been shown to have the potential for use as alternatives to chemical antimicrobials [150].

\section{Conclusion and Future Prospects}

Functional nucleic acids, chitosan, and antimicrobial peptides exhibit huge antibacterial potential and greatly reduce 
bacterial resistance. Compared with nonmodified molecules, the derivatives show stronger antibacterial activity after proper chemical and nanoparticle modification. As an alternative strategy, the development of antibacterial agents composed of biomolecules may provide a new way to avoid the current antibiotic resistance. Great progress and achievement have been made in understanding the antimicrobial mechanism with functional biomolecules in vitro. Some reports have shown significant efficacy in animal models of infection using doses in a clinically relevant range. We think that the future is bright for new antibacterial agents composed of functional biological molecules that has great potential in effect and are safe and nonresistant.

\section{Conflicts of Interest}

The authors declare that there are no conflicts of interest.

\section{Acknowledgments}

This work was supported by the Natural Science Foundation of Jiangsu Province (no. BK20181028), the Startup Foundation (GXL2014038), the Jiangsu Innovative Research Program for Talent from the World's Famous Universities, and the Priority Academic Program Development (PAPD) Program of Jiangsu Province at Nanjing Forestry University. This work was also funded by the Natural Science Foundation of the Jiangsu Higher Education Institutions of China (17KJB150011) and the Startup Foundation (JSNU2016YB02) at Jiangsu Second Normal University.

\section{References}

[1] M. S. Sinicropi, A. Caruso, F. Conforti et al., "Synthesis, inhibition of NO production and antiproliferative activities of some indole derivatives," Journal of Enzyme Inhibition and Medicinal Chemistry, vol. 24, no. 5, pp. 1148-1153, 2009.

[2] O. I. Parisi, M. Fiorillo, A. Caruso et al., "Enhanced cellular uptake by "pharmaceutically oriented devices" of new simplified analogs of Linezolid with antimicrobial activity," International Journal of Pharmaceutics, vol. 461, no. 1-2, pp. 163-170, 2014.

[3] A. Caruso, M. S. Sinicropi, J.-C. Lancelot et al., "Synthesis and evaluation of cytotoxic activities of new guanidines derived from carbazoles," Bioorganic \& Medicinal Chemistry Letters, vol. 24, no. 2, pp. 467-472, 2014.

[4] A. Farghaly and H. Kashef, "Synthesis of some new azoles with antiviral potential," Arkivoc, vol. 11, pp. 76-90, 2006.

[5] R. A. Khan, A. Tabacaru, F. Ali, and B. H. Koo, "Anticancer and antimicrobial properties of inorganic compounds/ nanomaterials," Bioinorganic Chemistry and Applications, vol. 10, 2019.

[6] D. Iacopetta, A. Mariconda, C. Saturnino et al., "Novel gold and silver carbene complexes exert antitumor effects triggering the reactive oxygen species dependent intrinsic apoptotic pathway," ChemMedChem, vol. 12, no. 24, pp. 2054-2065, 2017.

[7] O. I. Parisi, L. Scrivano, M. S. Sinicropi, and F. Puoci, "Polymeric nanoparticle constructs as devices for antibacterial therapy," Current Opinion in Pharmacology, vol. 36, pp. 72-77, 2017.
[8] P. A. Smith, M. F. T. Koehler, H. S. Girgis et al., "Optimized arylomycins are a new class of Gram-negative antibiotics," Nature, vol. 561, no. 7722, pp. 189-194, 2018.

[9] D. A. Rasko and V. Sperandio, "Anti-virulence strategies to combat bacteria-mediated disease," Nature Reviews Drug Discovery, vol. 9, no. 2, p. 117, 2010.

[10] G. Guidetti, A. Di Cerbo, A. Giovazzino et al., "In Vitro effects of some botanicals with anti-inflammatory and antitoxic activity," Journal of Immunology Research, vol. 2016, Article ID 5457010, 2016.

[11] E. E. Gill, O. L. Franco, and R. E. W. Hancock, “Antibiotic adjuvants: diverse strategies for controlling drug-resistant pathogens," Chemical Biology \& Drug Design, vol. 85, no. 1, pp. 56-78, 2015.

[12] J. F. Silva and R. J. Williams, The Biological Chemistry of the Elements: The Inorganic Chemistry of Life, Oxford University Press, Oxford, UK, 2001.

[13] M. Veerapandian and K. Yun, "Functionalization of biomolecules on nanoparticles: specialized for antibacterial applications," Applied Microbiology and Biotechnology, vol. 90, no. 5, pp. 1655-1667, 2011.

[14] S.-H. Lim and S. M. Hudson, "Review of chitosan and its derivatives as antimicrobial agents and their uses as textile chemicals," Journal of Macromolecular Science, Part C: Polymer Reviews, vol. 43, no. 2, pp. 223-269, 2003.

[15] K. Xing, X. Zhu, X. Peng, and S. Qin, "Chitosan antimicrobial and eliciting properties for pest control in agriculture: a review," Agronomy for Sustainable Development, vol. 35, no. 2, pp. 569-588, 2014.

[16] M. Mahlapuu, J. Hakansson, L. Ringstad, and C. Bjorn, "Antimicrobial peptides: an emerging category of therapeutic agents," Frontiers in Cellular and Infection Microbiology, vol. 6, p. 194, 2016.

[17] J. L. Narayana and J.-Y. Chen, "Antimicrobial peptides: possible anti-infective agents," Peptides, vol. 72, pp. 88-94, 2015.

[18] L.-j. Zhang and R. L. Gallo, "Antimicrobial peptides," Current Biology, vol. 26, no. 1, pp. R14-R19, 2016.

[19] E. K. Sully and B. L. Geller, "Antisense antimicrobial therapeutics," Current Opinion in Microbiology, vol. 33, pp. 47-55, 2016.

[20] P. Kalra, S. K. Mishra, S. Kaur et al., "G-QuadruplexForming DNA aptamers inhibit the DNA-binding function of HupB and Mycobacterium tuberculosis entry into host cells," Molecular Therapy-Nucleic Acids, vol. 13, pp. 99-109, 2018.

[21] B. P. Monia, J. F. Johnston, H. Sasmor, and L. L. Cummins, "Nuclease resistance and antisense activity of modified oligonucleotides targeted to Ha-ras," Journal of Biological Chemistry, vol. 271, no. 24, pp. 14533-14540, 1996.

[22] N. Dias and C. Stein, "Antisense oligonucleotides: basic concepts and mechanisms," Molecular Cancer Therapeutics, vol. 1, no. 5, pp. 347-355, 2002.

[23] R. Orr, "Technology evaluation: fomivirsen, Isis pharmaceuticals Inc/CIBA vision," Current Opinion in Molecular Therapeutics, vol. 3, no. 3, pp. 288-294, 2001.

[24] H. Kaur, A. Arora, J. Wengel, and S. Maiti, "Thermodynamic, counterion, and hydration effects for the incorporation of locked nucleic acid nucleotides into DNA duplexes," Biochemistry, vol. 45, no. 23, pp. 7347-7355, 2006.

[25] H. Kaur, A. Arora, J. Wengel, and S. Maiti, "Thermodynamic, counterion and hydration effects for the incorporation of locked nucleic acid (LNA) nucleotides in duplex," Nucleic Acids Symposium Series, vol. 2, pp. 425-426, 2008. 
[26] G. I. Hansen, T. Bentin, H. J. Larsen, and P. E. Nielsen, "Structural isomers of bis-PNA bound to a target in duplex DNA," Journal of Molecular Biology, vol. 307, no. 1, pp. 67-74, 2001.

[27] O. V. Krupnik, N. V. Fadeeva, N. P. Kvitko et al., "Stability and transformations of bis-PNA/DNA triplex structural isomers," Journal of Biomolecular Structure and Dynamics, vol. 21, no. 4, pp. 503-512, 2004.

[28] J. Hu and D. R. Corey, "Inhibiting gene expression with peptide nucleic acid (PNA)-peptide conjugates that target chromosomal DNA," Biochemistry, vol. 46, no. 25, pp. 7581-7589, 2007.

[29] F. Pellestor, P. Paulasova, and S. Hamamah, "Peptide nucleic acids (PNAs) as diagnostic devices for genetic and cytogenetic analysis," Current Pharmaceutical Design, vol. 14, no. 24, pp. 2439-2444, 2008.

[30] R. M. Hudziak, E. Barofsky, D. F. Barofsky, D. L. Weller, S.-B. Huang, and D. D. Weller, "Resistance of morpholino phosphorodiamidate oligomers to enzymatic degradation," Antisense and Nucleic Acid Drug Development, vol. 6, no. 4, pp. 267-272, 1996.

[31] S. Tantzer, K. Sperle, K. Kenaley, J. Taube, and G. M. Hobson, "Morpholino antisense oligomers as a potential therapeutic option for the correction of alternative splicing in PMD, SPG2, and HEMS," Molecular Therapy-Nucleic Acids, vol. 12, pp. 420-432, 2018.

[32] Y. Nan and Y. Zhang, "Antisense phosphorodiamidate morpholino oligomers as novel antiviral compounds," Frontiers in Microbiology, vol. 9, p. 750, 2018.

[33] P. E. Nielsen and M. Egholm, "An introduction to peptide nucleic acid," Current Issues in Molecular Biology, vol. 1, no. 1-2, pp. 89-104, 1999.

[34] L. Good, S. K. Awasthi, R. Dryselius, O. Larsson, and P. E. Nielsen, "Bactericidal antisense effects of peptide-PNA conjugates," Nature Biotechnology, vol. 19, no. 4, pp. 360364, 2001.

[35] S. Liang, Y. He, Y. Xia et al., "Inhibiting the growth of methicillin-resistant Staphylococcus aureus in vitro with antisense peptide nucleic acid conjugates targeting the ftsZ gene," International Journal of Infectious Diseases, vol. 30, pp. 1-6, 2015.

[36] D. Wesolowski, D. Alonso, and S. Altman, "Combined effect of a peptide-morpholino oligonucleotide conjugate and a cell-penetrating peptide as an antibiotic," Proceedings of the National Academy of Sciences, vol. 110, no. 21, pp. 86868689, 2013

[37] N. Patenge, R. Pappesch, F. Krawack et al., "Inhibition of growth and gene expression by PNA-peptide conjugates in Streptococcus pyogenes," Molecular Therapy Nucleic Acids, vol. 2, p. 132, 2013.

[38] J. Bruno, "A review of therapeutic aptamer conjugates with emphasis on new approaches," Pharmaceuticals, vol. 6, no. 3, pp. 340-357, 2013.

[39] J. Mehta, B. Van Dorst, E. Rouah-Martin et al., "In vitro selection and characterization of DNA aptamers recognizing chloramphenicol," Journal of Biotechnology, vol. 155, no. 4, pp. 361-369, 2011.

[40] H. Sun, X. Zhu, P. Y. Lu, R. R. Rosato, W. Tan, and Y. Zu, "Oligonucleotide aptamers: new tools for targeted cancer therapy," Molecular Therapy Nucleic Acids, vol. 3, 2014.

[41] O. S. Kolovskaya, A. G. Savitskaya, T. N. Zamay et al., "Development of bacteriostatic DNA aptamers for Salmonella," Journal of Medicinal Chemistry, vol. 56, no. 4, pp. 1564-1572, 2013.
[42] F. Sousa, C. Cruz, and J. A. Queiroz, "Amino acids-nucleotides biomolecular recognition: from biological occurrence to affinity chromatography," Journal of Molecular Recognition, vol. 23, no. 6, pp. 505-518, 2010.

[43] V. C. Özalp, K. Bilecen, M. Kavruk, and H. Avni Öktem, "Antimicrobial aptamers for detection and inhibition of microbial pathogen growth," Future Microbiology, vol. 8, no. 3, pp. 387-401, 2013.

[44] K. T. Shum, E. L. H. Lui, S. C. K. Wong et al., "Aptamermediated inhibition ofMycobacterium tuberculosisPolyphosphate kinase 2," Biochemistry, vol. 50, no. 15, pp. 3261-3271, 2011.

[45] M. Famulok, J. S. Hartig, and G. Mayer, "Functional aptamers and aptazymes in biotechnology, diagnostics, and therapy," Chemical Reviews, vol. 107, no. 9, pp. 3715-3743, 2007.

[46] H. Kaur, J. G. Bruno, A. Kumar, and T. K. Sharma, "Aptamers in the therapeutics and diagnostics pipelines," Theranostics, vol. 8, no. 15, pp. 4016-4032, 2018.

[47] M. Y. Song, J. Jurng, Y.-K. Park, and B. C. Kim, "An aptamer cocktail-functionalized photocatalyst with enhanced antibacterial efficiency towards target bacteria," Journal of Hazardous Materials, vol. 318, pp. 247-254, 2016.

[48] O. C. Farokhzad, "Nanotechnology for drug delivery: the perfect partnership," Expert Opinion on Drug Delivery, vol. 5, no. 9, pp. 927-929, 2008.

[49] C.-M. J. Hu, S. Aryal, and L. Zhang, "Nanoparticle-assisted combination therapies for effective cancer treatment," Therapeutic Delivery, vol. 1, no. 2, pp. 323-334, 2010.

[50] N. Gilbert and J. Allan, "Supercoiling in DNA and chromatin," Current Opinion in Genetics \& Development, vol. 25, pp. 15-21, 2014.

[51] J. J. Champoux, "DNA topoisomerases: structure, function, and mechanism," Annual Review of Biochemistry, vol. 70, no. 1, pp. 369-413, 2001.

[52] J. C. Wang, "DNA topoisomerases," Annual Review of Biochemistry, vol. 65, no. 1, pp. 635-692, 1996.

[53] S. K. Singh, S. Roy, S. Choudhury, and D. N. Sengupta, "DNA repair and recombination in higher plants: insights from comparative genomics of Arabidopsis and rice," $B M C \mathrm{Ge}$ nomics, vol. 11, no. 1, p. 443, 2010.

[54] J. L. Nitiss, "Investigating the biological functions of DNA topoisomerases in eukaryotic cells," Biochimica et Biophysica Acta (BBA)-Gene Structure and Expression, vol. 1400, no. 1-3, pp. 63-81, 1998.

[55] R. Madabhushi, "The roles of DNA topoisomerase II $\beta$ in transcription," International Journal of Molecular Sciences, vol. 19, no. 7, p. 1917, 2018.

[56] X. Liang, Q. Wu, S. Luan et al., "A comprehensive review of topoisomerase inhibitors as anticancer agents in the past decade," European Journal of Medicinal Chemistry, vol. 171, pp. 129-168, 2019.

[57] Y. Pommier, "DNA topoisomerase I inhibitors: chemistry, biology, and interfacial inhibition," Chemical Reviews, vol. 109, no. 7, pp. 2894-2902, 2009.

[58] B. Bradbury and M. Pucci, "Recent advances in bacterial topoisomerase inhibitors," Current Opinion in Pharmacology, vol. 8, no. 5, pp. 574-581, 2008.

[59] S. L. Badshah and A. Ullah, "New developments in nonquinolone-based antibiotics for the inhibiton of bacterial gyrase and topoisomerase IV," European Journal of Medicinal Chemistry, vol. 152, pp. 393-400, 2018.

[60] D. E. Ehmann and S. D. Lahiri, "Novel compounds targeting bacterial DNA topoisomerase/DNA gyrase," Current Opinion in Pharmacology, vol. 18, pp. 76-83, 2014. 
[61] D. Iacopetta, C. Rosano, F. Puoci et al., "Multifaceted properties of 1,4-dimethylcarbazoles: focus on trimethoxybenzamide and trimethoxyphenylurea derivatives as novel human topoisomerase II inhibitors," European Journal of Pharmaceutical Sciences, vol. 96, pp. 263-272, 2017.

[62] Y.-C. Tse-Dinh, "Bacterial topoisomerase I as a target for discovery of antibacterial compounds," Nucleic Acids Research, vol. 37, no. 3, pp. 731-737, 2009.

[63] Y.-C. Tse-Dinh, "Targeting bacterial topoisomerase I to meet the challenge of finding new antibiotics," Future Medicinal Chemistry, vol. 7, no. 4, pp. 459-471, 2015.

[64] S. Sandhaus, T. Annamalai, G. Welmaker et al., "Smallmolecule inhibitors targeting topoisomerase I as novel antituberculosis agents," Antimicrobial Agents and Chemotherapy, vol. 60, no. 7, pp. 4028-4036, 2016.

[65] Y. Zhang, J. H. Zhou, M. S. Ardejani, X. Li, F. Wang, and B. P. Orner, "Designability of aromatic interaction networks at E-coli bacterioferritin B-type channels," Molecules, vol. 22, no. 12, 2017.

[66] Z. Yang, T. Jiang, H. Zhong, and Y. Kang, "Bulge oligonucleotide as an inhibitory agent of bacterial topoisomerase I," Journal of Enzyme Inhibition and Medicinal Chemistry, vol. 33, no. 1, pp. 319-323, 2018.

[67] Z. Yang, T. Jiang, H. Zhong, and Y. Liu, "Portion mismatch in duplex oligonucleotides as inhibitors of bacterial topoisomerase I," RSC Advances, vol. 6, no. 109, pp. 107572107576, 2016.

[68] D. Li, Q. Wang, B. Zhou, Q. Zhuge, and B. Lv, "Small DNA circles as bacterial topoisomerase I inhibitors," RSC Advances, vol. 9, no. 32, pp. 18415-18419, 2019.

[69] S. Cansiz, L. Zhang, C. Wu et al., "DNA aptamer based nanodrugs: molecular engineering for efficiency," Chemistry-An Asian Journal, vol. 10, no. 10, pp. 2084-2094, 2015.

[70] J. Li, L. Mo, C.-H. Lu, T. Fu, H.-H. Yang, and W. Tan, "Functional nucleic acid-based hydrogels for bioanalytical and biomedical applications," Chemical Society Reviews, vol. 45, no. 5, pp. 1410-1431, 2016.

[71] S. Pavan and F. Berti, "Short peptides as biosensor transducers," Analytical and Bioanalytical Chemistry, vol. 402, no. 10, pp. 3055-3070, 2012.

[72] T. Nakatsuji and R. L. Gallo, "Antimicrobial peptides: old molecules with new ideas," Journal of Investigative Dermatology, vol. 132, no. 3, pp. 887-895, 2012.

[73] H. I. Zeya and J. K. Spitznagel, "Cationic proteins of polymorphonuclear leukocyte lysosomes II. Composition, properties, and mechanism of antibacterial action," Journal of Bacteriology, vol. 91, no. 2, pp. 755-762, 1966.

[74] R. Badolato, J. M. Wang, S.-L. Stornello, A. N. Ponzi, M. Duse, and T. Musso, "Serum amyloid A is an activator of PMN antimicrobial functions: induction of degranulation, phagocytosis, and enhancement of anti-candida activity," Journal of Leukocyte Biology, vol. 67, no. 3, pp. 381-386, 2000.

[75] J. R. Keast, "Mucosal innervation and control of water and ion transport in the intestine," Reviews of Physiology, Biochemistry and Pharmacology, vol. 109, pp. 1-59, 1987.

[76] M. Zasloff, "Magainins, a class of antimicrobial peptides from Xenopus skin: isolation, characterization of two active forms, and partial cDNA sequence of a precursor," Proceedings of the National Academy of Sciences, vol. 84, no. 15, pp. 5449-5453, 1987.

[77] G. Wang, X. Li, and Z. Wang, "APD3: the antimicrobial peptide database as a tool for research and education," Nucleic Acids Research, vol. 44, no. D1, pp. D1087-D1093, 2016.
[78] Z. Wang and G. Wang, "APD: the antimicrobial peptide database," Nucleic Acids Research, vol. 32, pp. D590-D592, 2004.

[79] I. Zelezetsky, A. Pontillo, L. Puzzi et al., "Evolution of the primate cathelicidin," Journal of Biological Chemistry, vol. 281, no. 29, pp. 19861-19871, 2006.

[80] D. Romeo, B. Skerlavaj, M. Bolognesi, and R. Gennaro, "Structure and bactericidal activity of an antibiotic dodecapeptide purified from bovine neutrophils," The Journal of Biological Chemistry, vol. 263, no. 20, pp. 9573-9575, 1988.

[81] B. Skerlavaj, R. Gennaro, L. Bagella, L. Merluzzi, A. Risso, and M. Zanetti, "Biological characterization of two novel cathelicidin-derived peptides and identification of structural requirements for their antimicrobial and cell lytic activities," Journal of Biological Chemistry, vol. 271, no. 45, pp. 28375-28381, 1996.

[82] A. van Dijk, E. J. A. Veldhuizen, A. van Asten, and H. P. Haagsman, "CMAP27, a novel chicken cathelicidin-like antimicrobial protein," Veterinary Immunology and Immunopathology, vol. 106, no. 3-4, pp. 321-327, 2005.

[83] M. Zanetti, P. Storici, A. Tossi, M. Scocchi, and R. Gennaro, "Molecular cloning and chemical synthesis of a novel antibacterial peptide derived from pig myeloid cells," The Journal of Biological Chemistry, vol. 269, no. 11, pp. 78557858, 1994.

[84] H. Tamamura, T. Murakami, S. Horiuchi et al., "Synthesis of protegrin-related peptides and their antibacterial and antihuman immunodeficiency virus activity," Chemical \& Pharmaceutical Bulletin, vol. 43, no. 5, pp. 853-858, 1995.

[85] P. Casteels, C. Ampe, L. Riviere et al., "Isolation and characterization of abaecin, a major antibacterial response peptide in the honeybee (Apis mellifera)," European Journal of Biochemistry, vol. 187, no. 2, pp. 381-386, 1990.

[86] H. Oh, M. Hedberg, D. Wade, and C. Edlund, "Activities of synthetic hybrid peptides against anaerobic bacteria: aspects of methodology and stability," Antimicrobial Agents and Chemotherapy, vol. 44, no. 1, pp. 68-72, 2000.

[87] S. Kaewklom, J. Euanorasetr, B. Intra, W. Panbangred, and R. Aunpad, "Antimicrobial activities of novel peptides derived from defensin genes of Brassica hybrid cv Pule," International Journal of Peptide Research and Therapeutics, vol. 22, no. 1, pp. 93-100, 2015.

[88] R. B. Samriti and K. Biswas, "Antibacterial activity of antimicrobial peptide extracted from Trianthema portulacastrum Leaves," The Pharma Innovation Journal, vol. 8, no. 3, pp. 81-86, 2019.

[89] A.-G. Gao, S. M. Hakimi, C. A. Mittanck et al., "Fungal pathogen protection in potato by expression of a plant defensin peptide," Nature Biotechnology, vol. 18, no. 12, pp. 1307-1310, 2000.

[90] K.-F. Lin, T.-R. Lee, P.-H. Tsai, M.-P. Hsu, C.-S. Chen, and P.-C. Lyu, "Structure-based protein engineering for $\alpha-$ amylase inhibitory activity of plant defensin," Proteins: Structure, Function, and Bioinformatics, vol. 68, no. 2, pp. 530-540, 2007.

[91] A. Segura, M. Moreno, F. Madueño, A. Molina, and F. García-Olmedo, "Snakin-1, a peptide from potato that is active against plant pathogens," Molecular Plant-Microbe Interactions, vol. 12, no. 1, pp. 16-23, 1999.

[92] P. Baindara, V. Chaudhry, G. Mittal et al., "Characterization of the antimicrobial peptide penisin, a class ia novel lantibiotic from paenibacillus sp. strain A3," Antimicrobial Agents and Chemotherapy, vol. 60, no. 1, pp. 580-591, 2016.

[93] Y. Urade and O. Hayaishi, "Biochemical, structural, genetic, physiological, and pathophysiological features of lipocalin- 
type prostaglandin D synthase," Biochimica et biophysica acta, vol. 1482, no. 1-2, pp. 259-271, 2000.

[94] J. T. Henderson, A. L. Chopko, and P. D. van Wassenaar, "Purification and primary structure of pediocin PA-1 produced by Pediococcus acidilactici PAC-1.0," Archives of Biochemistry and Biophysics, vol. 295, no. 1, pp. 5-12, 1992.

[95] P. K. Singh, S. Sharma, A. Kumari, and S. Korpole, "A nonpediocin low molecular weight antimicrobial peptide produced by Pediococcus pentosaceus strain IE-3 shows increased activity under reducing environment," $B M C$ Microbiology, vol. 14, no. 1, p. 226, 2014.

[96] J. Borrero, D. A. Brede, M. Skaugen et al., "Characterization of garvicin ML, a novel circular bacteriocin produced byLactococcus garvieaeDCC43, isolated from mallard ducks (Anas platyrhynchos)," Applied and Environmental Microbiology, vol. 77, no. 1, pp. 369-373, 2011.

[97] O. Kilsgård, P. Andersson, M. Malmsten et al., "Peptidylarginine deiminases present in the airways during tobacco smoking and inflammation can citrullinate the host defense peptide LL-37, resulting in altered activities," American Journal of Respiratory Cell and Molecular Biology, vol. 46, no. 2, pp. 240-248, 2012.

[98] E. Veldhuizen, M. Scheenstra, J. Bokhoven et al., "Antimicrobial and immunomodulatory activity of PMAP-23 derived peptides," Protein and Peptide Letters, vol. 24, no. 7, pp. 609-616, 2017.

[99] A. Scheid, N. Li, C. Jeffers et al., "Antimicrobial peptide LL37 and recombinant human mannose-binding lectin express distinct age- and pathogen-specific antimicrobial activity in human newborn cord blood in vitro," F1000Research, vol. 7, p. 616, 2018.

[100] A. Baumann, M. S. Kiener, B. Haigh, V. Perreten, and A. Summerfield, "Differential ability of bovine antimicrobial cathelicidins to mediate nucleic acid sensing by epithelial cells," Front Immunol, vol. 8, p. 59, 2017.

[101] M. Scheenstra, M. Belt, J. Bokhoven et al., "Cathelicidins PMAP-36, LL-37 and CATH-2 are similar peptides with different modes of action," Scientific Reports, vol. 9, no. 1, p. $4780,2019$.

[102] Y. Lyu, Y. Yang, X. Lyu, N. Dong, and A. Shan, "Antimicrobial activity, improved cell selectivity and mode of action of short PMAP-36-derived peptides against bacteria and candida," Scientific Reports, vol. 6, p. 27285, 2016.

[103] M. Rahnamaeian, M. Cytrynska, A. Barabas et al., "Insect antimicrobial peptides show potentiating functional interactions against gram-negative bacteria," Proceedings of the Royal Society B: Biological Sciences, vol. 282, no. 1806, Article ID 20150293, 2015.

[104] B. S. McGwire and M. M. Kulkarni, "Interactions of antimicrobial peptides with Leishmania and trypanosomes and their functional role in host parasitism," Experimental Parasitology, vol. 126, no. 3, pp. 397-405, 2010.

[105] J. Tam, S. Wang, K. Wong, and W. Tan, "Antimicrobial peptides from plants," Pharmaceuticals, vol. 8, no. 4, pp. 711-757, 2015.

[106] V. Le Sage, L. Zhu, C. Lepage et al., “An outer membrane protease of the omptin family prevents activation of theCitrobacter rodentiumPhoPQ two-component system by antimicrobial peptides," Molecular Microbiology, vol. 74, no. 1, pp. 98-111, 2009.

[107] J. S. Sandhu, M. K. Sidhu, and I. S. Yadav, "Control of fungal diseases in agricultural crops by chitinase and glucanase transgenes," Sustainable Agriculture Reviews, vol. 3, pp. 163-212, 2017.
[108] A. Badrhadad, F. Nazarian-Firouzabadi, and A. Ismaili, "Fusion of a chitin-binding domain to an antibacterial peptide to enhance resistance to Fusarium solani in tobacco (Nicotiana tabacum)," 3 Biotech, vol. 8, no. 9, p. 391, 2018.

[109] W. Woraprayote, Y. Malila, S. Sorapukdee, A. Swetwiwathana, S. Benjakul, and W. Visessanguan, "Bacteriocins from lactic acid bacteria and their applications in meat and meat products," Meat Science, vol. 120, pp. 118-132, 2016.

[110] W. C. Chan, M. Leyland, J. Clark et al., "Structure-activity relationships in the peptide antibiotic nisin: antibacterial activity of fragments of nisin," FEBS Letters, vol. 390, no. 2, pp. 129-132, 1996.

[111] M. Turgis, D. Khanh, J. Majid, M. Behnoush, and L. Monique, "Synergistic antimicrobial effect of combined bacteriocins against food pathogens and spoilage bacteria," International Journal of Microbiology, vol. 4, no. 1, pp. 1-5, 2016.

[112] H. Chi and H. Holo, "Synergistic antimicrobial activity between the broad spectrum bacteriocin garvicin KS and nisin, farnesol and polymyxin B against gram-positive and gram-negative bacteria," Current Microbiology, vol. 75, no. 3, pp. 272-277, 2018.

[113] S. T. Haldorsen, "Screening for antimicrobials against Staphylococcus aureus and Pseudomonas aeruginosa in fermented fruit and vegetables," Norwegian University of Life Sciences, vol. 2, 2017.

[114] S. D. Todorov, B. D. G. de Melo Franco, and J. Tagg, "Bacteriocins of Gram-positive bacteria having activity spectra extending beyond closely-related species," Beneficial Microbes, vol. 10, no. 3, pp. 315-328, 2019.

[115] D. P. Mohanty, S. Mohapatra, S. Misra, and P. S. Sahu, "Milk derived bioactive peptides and their impact on human health-a review," Saudi Journal of Biological Sciences, vol. 23, no. 5, pp. 577-583, 2016.

[116] Y. Zhang, Y. X. Dong, J. H. Zhou, X. Li, and F. Wang, "Application of plant viruses as a biotemplate for nanomaterial fabrication," Molecules, vol. 23, no. 9, 2018.

[117] O. Toke, "Antimicrobial peptides: new candidates in the fight against bacterial infections," Biopolymers, vol. 80, no. 6, pp. 717-735, 2005.

[118] Y. Shai, "Mechanism of the binding, insertion and destabilization of phospholipid bilayer membranes by alpha-helical antimicrobial and cell non-selective membrane-lytic peptides," Biochimica et biophysica acta, vol. 1462, no. 1-2, pp. 55-70, 1999.

[119] T. Lee, K. Hall, and M. Aguilar, "Antimicrobial peptide structure and mechanism of action: a focus on the role of membrane structure," Current Topics in Medicinal Chemistry, vol. 16, no. 1, pp. 25-39, 2016.

[120] C. Dart, "Symposium review: lipid microdomains and the regulation of ion channel function," The Journal of Physiology, vol. 588, no. 17, pp. 3169-3178, 2010.

[121] P. Kumar, J. N. Kizhakkedathu, and S. K. Straus, "Antimicrobial peptides: diversity, mechanism of action and strategies to improve the activity and biocompatibility in vivo," Biomolecules, vol. 8, no. 1, 2018.

[122] R. Riva, H. Ragelle, A. Rieux, N. Duhem, C. Jerome, and V. Preat, "Chitosan and chitosan derivatives in drug delivery and tissue engineering," Chitosan for Biomaterials II, vol. 1, pp. 19-44, 2011.

[123] L. N. Remedio, J. W. Silva dos Santos, V. B. Vieira Maciel, C. M. P. Yoshida, and R. Aparecida de Carvalho, "Characterization of active chitosan films as a vehicle of potassium 
sorbate or nisin antimicrobial agents," Food Hydrocolloids, vol. 87, pp. 830-838, 2019.

[124] K.-M. Yeon, J. You, M. D. Adhikari et al., "Enzymeimmobilized chitosan nanoparticles as environmentally friendly and highly effective antimicrobial agents," Biomacromolecules, vol. 20, no. 7, pp. 2477-2485, 2019.

[125] Z. Ma, A. Garrido-Maestu, and K. C. Jeong, "Application, mode of action, and in vivo activity of chitosan and its microand nanoparticles as antimicrobial agents: a review," Carbohydrate Polymers, vol. 176, pp. 257-265, 2017.

[126] E. I. Rabea, M. E.-T. Badawy, C. V. Stevens, G. Smagghe, and W. Steurbaut, "Chitosan as antimicrobial agent: applications and mode of action," Biomacromolecules, vol. 4, no. 6, pp. 1457-1465, 2003.

[127] H. Sashiwa and S.-I. Aiba, "Chemically modified chitin and chitosan as biomaterials," Progress in Polymer Science, vol. 29, no. 9, pp. 887-908, 2004.

[128] T. Ahmed and B. Aljaeid, "Preparation, characterization, and potential application of chitosan, chitosan derivatives, and chitosan metal nanoparticles in pharmaceutical drug delivery," Drug Design, Development and Therapy, vol. 10, pp. 483-507, 2016.

[129] J. Hoque, U. Adhikary, V. Yadav et al., "Chitosan derivatives active against multidrug-resistant bacteria and pathogenic fungi: in vivo evaluation as topical antimicrobials," Molecular Pharmaceutics, vol. 13, no. 10, pp. 3578-3589, 2016.

[130] Z. Sun, C. Shi, X. Wang, Q. Fang, and J. Huang, "Synthesis, characterization, and antimicrobial activities of sulfonated chitosan," Carbohydrate Polymers, vol. 155, pp. 321-328, 2017.

[131] J.-Y. Je and S.-K. Kim, "Antimicrobial action of novel chitin derivative," Biochimica et Biophysica Acta (BBA)-General Subjects, vol. 1760, no. 1, pp. 104-109, 2006.

[132] L. Pei, Z. Cai, S. Shang, and Z. Song, "Synthesis and antibacterial activity of alkylated chitosan under basic ionic liquid conditions," Journal of Applied Polymer Science, vol. 131, no. 7, 2014.

[133] B. Shagdarova, A. Lunkov, A. Il'ina, and V. Varlamov, "Investigation of the properties of $\mathrm{N}$-[(2-hydroxy-3-trimethylammonium) propyl] chloride chitosan derivatives," International Journal of Biological Macromolecules, vol. 124, pp. 994-1001, 2019.

[134] O. M. Dragostin, S. K. Samal, M. Dash et al., "New antimicrobial chitosan derivatives for wound dressing applications," Carbohydrate Polymers, vol. 141, pp. 28-40, 2016.

[135] M. Wu, Z. Long, H. Xiao, and C. Dong, "Recent research progress on preparation and application of N,N.N-trimethyl chitosan," Carbohydrate Research, vol. 434, pp. 27-32, 2016.

[136] P. K. Dutta, S. Tripathi, G. K. Mehrotra, and J. Dutta, "Perspectives for chitosan based antimicrobial films in food applications," Food Chemistry, vol. 114, no. 4, pp. 1173-1182, 2009.

[137] E. Munoz, L. Averous, G. Santillan et al., "EDC-mediated grafting of quaternary ammonium salts onto chitosan for antibacterial and thermal properties improvement," Macromolecular Chemistry and Physics, vol. 220, no. 8, 2019.

[138] Z. Guo, R. Xing, S. Liu et al., "The influence of molecular weight of quaternized chitosan on antifungal activity," Carbohydrate Polymers, vol. 71, no. 4, pp. 694-697, 2008.

[139] H. Liu, X. Liu, L. Yue, Q. Jiang, and W. Xia, "Synthesis, characterization and bioactivities of $\mathrm{N}, \mathrm{O}$-carbonylated chitosan," International Journal of Biological Macromolecules, vol. 91, pp. 220-226, 2016.

[140] Q. L. Feng, J. Wu, G. Q. Chen, F. Z. Cui, T. N. Kim, and J. O. Kim, "A mechanistic study of the antibacterial effect of silver ions onEscherichia coli andStaphylococcus aureus," Journal of Biomedical Materials Research, vol. 52, no. 4, pp. 662-668, 2000.

[141] R. Kalaivani, M. Maruthupandy, T. Muneeswaran et al., "Synthesis of chitosan mediated silver nanoparticles (Ag NPs) for potential antimicrobial applications," Frontiers in Laboratory Medicine, vol. 2, no. 1, pp. 30-35, 2018.

[142] P. P. Fu, Q. Xia, H.-M. Hwang, P. C. Ray, and H. Yu, "Mechanisms of nanotoxicity: generation of reactive oxygen species," Journal of Food and Drug Analysis, vol. 22, no. 1, pp. 64-75, 2014.

[143] M. Malini, M. Thirumavalavan, W.-Y. Yang, J.-F. Lee, and G. Annadurai, "A versatile chitosan/ZnO nanocomposite with enhanced antimicrobial properties," International Journal of Biological Macromolecules, vol. 80, pp. 121-129, 2015.

[144] P. M. Rahman, V. M. A. Mujeeb, K. Muraleedharan, and S. K. Thomas, "Chitosan/nano $\mathrm{ZnO}$ composite films: enhanced mechanical, antimicrobial and dielectric properties," Arabian Journal of Chemistry, vol. 11, no. 1, pp. 120-127, 2018.

[145] N. A. A. Yusof, N. M. Zain, and N. Pauzi, "Synthesis of ZnO nanoparticles with chitosan as stabilizing agent and their antibacterial properties against Gram-positive and Gramnegative bacteria," International Journal of Biological Macromolecules, vol. 124, pp. 1132-1136, 2019.

[146] J. Li, Y. Wu, and L. Zhao, "Antibacterial activity and mechanism of chitosan with ultra high molecular weight," Carbohydrate Polymers, vol. 148, pp. 200-205, 2016.

[147] R. C. Goy, D. d. Britto, and O. B. G. Assis, "A review of the antimicrobial activity of chitosan," Polímeros, vol. 19, no. 3, pp. 241-247, 2009.

[148] A. Gomes, J. Mano, and J. Queiroz, Assessement of BacteriaTextile Interactions Using Scanning Electron Microscopy: A Study on LbL Chitosan/alginate Coated Cotton, Formatex Research Center, Badajoz, Spain, 2010.

[149] L. Hadwiger, D. Kendra, B. Fristensky, and W. Wagoner, "Chitosan both activates genes in plants and inhibits RNA synthesis in fungi," Chitin in Nature and Technology, vol. 10, pp. 209-214, 1986.

[150] M. Aziz and S. Karboune, "Natural antimicrobial/antioxidant agents in meat and poultry products as well as fruits and vegetables: a review," Critical Reviews in Food Science and Nutrition, vol. 58, no. 3, pp. 486-511, 2018. 